$11-1-2000$

\title{
Tibiocalcaneal Kinematics of Barefoot Versus Shod Running
}

Alex Stacoff

University of Calgary, stacoff@biomech.mat.ethz.ch

Benno M. Nigg

University of Calgary

Christoph Reinschmidt

University of Calgary

Antonie J. van den Bogert

Cleveland State University, a.vandenbogert@csuohio.edu

Asnew-thnslaRGGGadditional works at: https://engagedscholarship.csuohio.edu/enme_facpub Iniversity Hospital, Huddinge, Sweden

Part of the Biomechanical Engineering Commons

How does access to this work benefit you? Let us know!

Publisher's Statement

NOTICE: this is the author's version of a work that was accepted for publication in Journal of Biomechanics. Changes resulting from the publishing process, such as peer review, editing, corrections, structural formatting, and other quality control mechanisms may not be reflected in this document. Changes may have been made to this work since it was submitted for publication. A definitive version was subsequently published in Journal of Biomechanics, 33, 11, (11-01-2000); 10.1016/S0021-9290(00)00116-0

\section{Original Citation}

Stacoff, A., Nigg, B. M., Reinschmidt, C., 2000, "Tibiocalcaneal Kinematics of Barefoot Versus Shod Running," Journal of Biomechanics, 33(11) pp. 1387-1395.

This Article is brought to you for free and open access by the Mechanical Engineering Department at EngagedScholarship@CSU. It has been accepted for inclusion in Mechanical Engineering Faculty Publications by an authorized administrator of EngagedScholarship@CSU. For more information, please contact library.es@csuohio.edu. 


\title{
Tibiocalcaneal kinematics of barefoot versus shod running
}

\author{
Alex Stacoff ${ }^{\mathrm{a}, \mathrm{b}, *}$, Benno M. Nigg ${ }^{\mathrm{a}}$, Christoph Reinschmidt ${ }^{\mathrm{a}, \mathrm{c}}$, Anton J. van den Bogert ${ }^{\mathrm{a}, \mathrm{d}}$, \\ Arne Lundberg ${ }^{\mathrm{e}}$ \\ ${ }^{2}$ Human Performance Laboratory, The University of Calgary, Canada \\ 'Biomechanics Laboratory, ETH Zürich, Schlieren, Switzerland

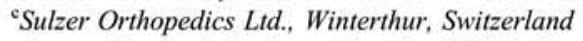 \\ ${ }^{\mathrm{d} B i o m e d i c a l}$ Engineering, Lerner Research Institute, Cleveland Clinic Foundation, Cleveland, USA \\ 'Department of Orthopaedics, Karolinska Institute, University Hospital, Huddinge, Sweden
}

\section{Introduction}

Lower extremity movements of excessive eversion and tibial rotation have been associated with various running injuries (Clement et al., 1981; James et al., 1978; Segesser and Nigg, 1980; Viitasalo and Kvist, 1983; van Mechelen, 1992). Furthermore, movement coupling between the foot and shank, which results in the tibia rotating internally between touchdown and midstance, has recently been associated with running injuries (Nigg et al., 1993; Stergiou, 1996; McClay and Manal, 1997).

\footnotetext{
* Correspondence address: Department of Materials, Laboratory for Biomechanics, ETH Zürich, Wagistrasse 4, 8952 Schlieren, Switzerland. Tel.: + 41-1-633-6211; fax: + 41-1-633-1124.

E-mail address: stacoff@biomech.mat.ethz.ch (A. Stacoff).
}

Foot orthoses and shoe sole modifications have been proposed to reduce excessive movements of foot and shank (James et al., 1978; Bates et al., 1978; Clarke et al., 1984; Segesser and Nigg, 1980; van Woensel and Cavanagh, 1992; Nigg and Morlock, 1987; Milani et al., 1995). Most of these studies used a two-dimensional analysis that has been shown to be affected by the alignment of the foot with respect to the camera (Areblad et al., 1990). Additionally, the majority of these studies used shoe- and skin-mounted markers that are known to overestimate the skeletal movements (Cappozzo et al., 1996; Reinschmidt et al., 1997). Thus, the results of these studies may not have reflected the kinematics of the underlying bone.

Running with shoes may change foot and leg kinematics compared to running barefoot. Hence, barefoot running is often looked upon as the baseline for normal running (Clarke et al., 1984). In barefoot running the foot 
has been shown to invert less at touchdown and to have decreased maximum eversion velocity and total eversion compared to shod running (Bates et al., 1978; Stacoff et al., 1991; Vagenas and Hoshizaki, 1992). Thus, tibial rotations may be assumed to be decreased in barefoot running compared to shod running (assuming that movement coupling in barefoot and shod running does not differ). Consequently, it may be suggested that barefoot running could lead to fewer running injuries than shod running, provided there are no additional injuries from the lack of foot protection. To date, tibial rotation of barefoot running has not been documented in the literature and the suggestion about possible advantages and/or disadvantages of barefoot running lacks information on the skeletal movement during barefoot or shod movements, possible changes in muscle activity and epidemiological data.

The purpose of this study was to quantify three-dimensional skeletal movement differences between barefoot and shod running using markers fixed to bone pins during the stance phase of running. Skeletal movements of barefoot running are expected to show decreased total calcaneal eversion, decreased total tibial rotation, and unchanged tibiocalcaneal coupling.

\section{Methods}

\subsection{General project description}

The experiments were performed in the Department of Orthopaedics, Karolinska Institute at Huddinge University Hospital, Stockholm. The experiments were approved by the Ethics committees of the Karolinska Hospital and The University of Calgary. The experimental set-up, test procedure, data analysis and data reduction have already been described earlier (Reinschmidt, 1996; Reinschmidt et al., 1997; Stacoff et al., 2000).

Briefly, five healthy male volunteers, all injury free with no previous injury history that might influence their locomotion patterns, participated as test subjects $(28.6 \pm 4.3 \mathrm{yr}, \quad$ mass $83.4 \pm 10.2 \mathrm{~kg}$ and height $185.1 \pm 4.5 \mathrm{~cm}$ ) with clinically normal feet. Intracortical Hofmann pins with reflective marker triads were inserted under standard local anesthetic which was active for $2-3 \mathrm{~h}$, leaving enough time for the experiments. The subjects gave their informed consent to participate in the study and performed heel-toe running trials at a speed between 2.5 and $3.0 \mathrm{~m} / \mathrm{s}$. To accustom to the conditions the subjects performed several trials before testing. The runway was $9.35 \mathrm{~m}$ long, allowing a $4.35 \mathrm{~m}$ run-up to the filming area and enough room to continue and stop. Test trials were repeated if the subjects missed the filming area and/or if they obviously changed their gait pattern. Three high-speed cine cameras (LOCAM) were placed around a force platform (KISTLER) mounted flush to the runway. The camera speed was set at $200 \mathrm{~Hz}$ and three LED's, triggered by a threshold detector connected to the force plate, were used to synchronize the cameras. A calibration frame with six control points $\left(0.5 \times 0.5 \times 0.5 \mathrm{~m}^{3}\right)$ was used for the three-dimensional reconstruction.

\subsection{Test conditions, shoes and orthoses}

The tests were performed barefoot, with a normal test shoe and with five modifications of the normal test shoe. The normal test shoe (Adidas Equipment Cushioning) had a dual density midsole of Shore A 35 on the lateral and Shore A 45 on the medial side and a standard insert which was assumed to have no mechanical support for the foot. The standard insert was exchanged with two orthoses, one anterior to support the foot arch and one posterior to support the sustentaculum tali of the calcaneus. The remaining three modifications concerned the shoe sole which was changed to a single density midsole (Shore A 45). The lateral heel flare was modified with a wide flare, a neutral flare and a rounded sole. The outer sole consisted of a hard rubber sole of Shore A 65. The different shoes and orthoses used have been explained in Stacoff (1998) and Stacoff et al. (2000). Each test condition was repeated three times, respectively (except for the normal shoe condition with five repetitions). The subjects performed a total of 23 running trials. All shoe heel counters had a lateral cutout to prevent impingement with the calcaneal bone pin during running as described previously.

\subsection{Data analysis and reduction}

KineMat, a set of programs written in MATLAB ${ }^{\mathrm{TM}}$, was adapted from Reinschmidt (1996) for the specific needs of this investigation. The programs served to reconstruct the three-dimensional marker positions and to calculate the relative segmental movements. The barefoot standing trial was used as the neutral position to define the segment-fixed coordinate systems of the calcaneus and tibia (Reinschmidt et al., 1997). For that purpose the subjects were instructed to stand with straight knees, the ankle in neutral position of $90^{\circ}$ dorsiflexion and the feet aligned parallel to the force platform representing the laboratory coordinate system. This procedure made possible errors (e.g. kinematic cross-talk) systematic within each subject and allowed the comparison of different test conditions. Kinematic cross-talk between calcaneus and tibia was estimated to be in the order of $\pm 1^{\circ}$ (Stacoff, 1998). Rotations between segments were calculated as Cardanic angles for the stance phase of all test conditions using a joint coordinate system approach (JCS) at the ankle joint complex, with the defined sequence of rotations of plantar/dorsiflexion about a tibia fixed mediolateral axis, calcaneal ab/adduction about the floating 
axis, and in/eversion about the antero-posterior axis of the calcaneus (Cole et al., 1993). Tibial rotation was calculated using the sequence: tibial rotation about a tibia fixed proximal-distal axis, in/eversion about the floating axis, and plantar/dorsiflexion about a calcaneus fixed medio-lateral axis (Nigg et al., 1993).

The accuracy of the spatial reconstruction between two marker triads was determined twice: (i) based on the residuals of the DLT equations averaged over the entire stance phase and was found to be in the order of $\pm 4^{\circ}$ (including noise error and lens distortion error, and (ii) based on the deviations of the inter-marker distances of the same trials where the mean error (RMS) was found to be $\pm 1.0^{\circ}$ (including noise error only). Thus, for the present study, a realistic estimation of the error was likely between the two errors given above.

\subsection{Definitions of variables}

In/eversion and tibial rotation variable definitions are explained in Table 1 and in Reinschmidt et al. (1997) and Stacoff et al. (2000). The variables were defined between touchdown and midstance of running. The inversion positions at touchdown $\left(\beta_{0}\right.$, and $\left.\rho_{0}\right)$ were considered to detect possible adaptations to shoe interventions before touchdown. Excessive eversion (i.e. $\beta_{\max }$ and $\Delta \beta_{\max }$ ) has been suggested to force the Achilles tendon to bend laterally, hereby producing an asymmetric stress distribution across the tendon which could lead to Achilles tendon problems (Clement et al., 1981). Excessive eversion velocity $\dot{\beta}_{\max }$ has been associated with medial tibial stress syndrome (Segesser and Nigg, 1980; Viitasalo et al., 1993). Excessive tibial rotation $\left(\Delta \rho_{\max }\right)$ has been associated with changes in the tracking of the patella which may be related to the occurrence of the patellafemoral pain syndrome (Stergiou, 1996). Movement coupling at the ankle describes how much movement occurs about the tibia fixed external/internal axis relative to the simultaneous rotation about the calcaneus fixed eversion/inversion axis). The coupling coefficient was defined as the ratio of total internal tibial rotation over total eversion. This coefficient has been used in previous in vitro studies (Olerud and Rosendahl, 1985; Hintermann, 1994) and in-vivo studies (Lundberg, 1989; Nigg et al., 1993; McClay and Manal, 1997). Movement coupling at the ankle has been described to be dependent on vertical loading, plantar/dorsiflexion, ligament integrity, and musculo-tendon forces (Hintermann, 1994). Thus, in contrast to a rigid

Table 1

Definition and functional explanation of the study variables. The shoe variables were defined accordingly

\begin{tabular}{llll}
\hline Variable & Symbol & Definition & Justification \\
\hline - Touchdown in/eversion & $\beta_{0}$ & $\begin{array}{l}\text { In/eversion position of calcaneus (relative } \\
\text { to tibia) and tibial rotation position }\end{array}$ & $\begin{array}{l}\text { Shoe modifications may affect } \\
\text { calcaneal and tibial position } \\
\text { before touchdown changing the } \\
\text { initial conditions }\end{array}$ \\
& & &
\end{tabular}

- Touchdown tibial rotation

- Maximum eversion

$\beta_{\max }$

$\Delta \beta_{\max }$

- Total eversion

- Maximum eversion velocity

$\dot{\beta}_{\max }$

- Maximum internal tibial rotation

$\rho_{\max }$

$\Delta \rho_{\max }$

- Total internal tibial rotation

- Max. internal tibial rotation velocity
Maximum eversion of calcaneus (relative to tibia) during ground contact $=\beta_{\max }-\beta_{0}$

Maximum eversion velocity of calcaneus between 10 and $40 \%$ of ground contact

Maximum internal tibial rotation (relative to calcaneus) during ground contact

$$
=\rho_{\max }-\rho_{0}
$$

Maximum internal tibial rotation velocity between 10 and $40 \%$ of ground contact
- Excessive eversion has been associated with Achilles tendon problems

- Excessive eversion velocity has been associated with medial tibial stress syndrome

- Excessive eversion transferred to excessive internal tibial rotation

- Excessive tibial rotation has been associated with patella-femoral pain syndrome

- Excessive eversion velocity transferred to excessive internal tibial rotation velocity 

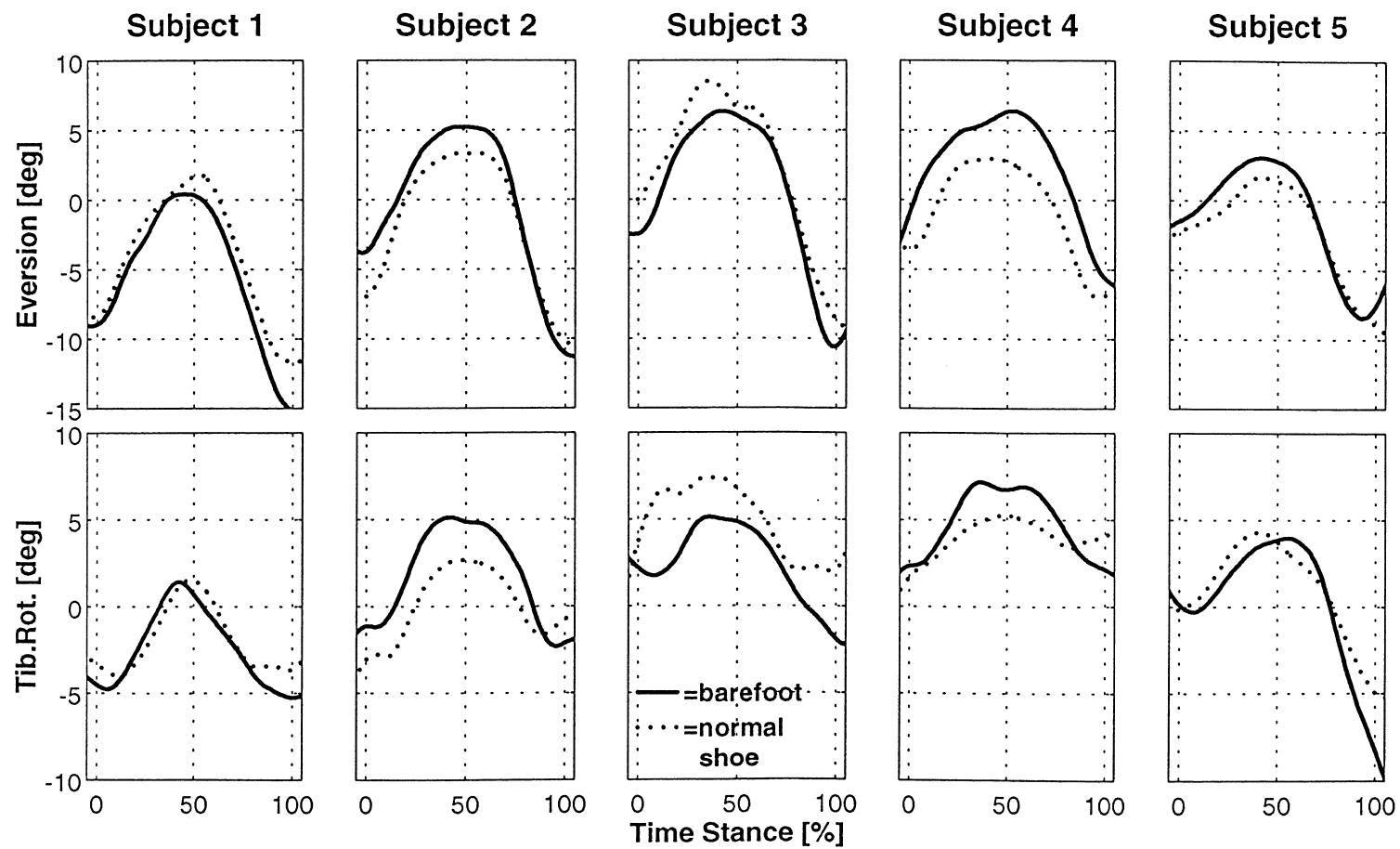

Fig. 1. Mean curves of in/eversion and tibial rotation of all conditions and all subjects: ( - ) barefoot (•••) normal shoe. The standard deviation during the stance phase was on average $\pm 1.1^{\circ}$ for eversion and tibial rotation. The barefoot condition was repeated three times, the normal shoe condition five times.

mechanical gear, movement coupling at the ankle is likely to be non-rigid during the stance phase of running.

The testing procedure was organised such that test conditions were independent of each other. All variables of the present study were found not to contradict the assumption of normal distribution performing the Kolmogorov-Smirnov test over all 115 trials.

\section{Results}

The results are presented in two parts: Section 3.1 gives a comparison between barefoot and shod running using the "normal" shoe, and Section 3.2 deals with a similar comparison using all shoe modifications.

\subsection{Barefoot versus shod running}

Eversion and internal tibial rotation took place from touchdown until midstance, and inversion and external tibial rotation took place from midstance to take-off in all subjects. Fig. 1 shows the mean curves of the barefoot and shod condition. The movement patterns were found to be consistent over trials, varying about $\pm 1^{\circ}$ between trials (Reinschmidt et al., 1997; Stacoff et al., 2000). Movement coupling for the barefoot and shod was found to be similar (Fig. 2).

Interindividual differences in total calcaneal eversion and total internal tibial rotation during ground contact
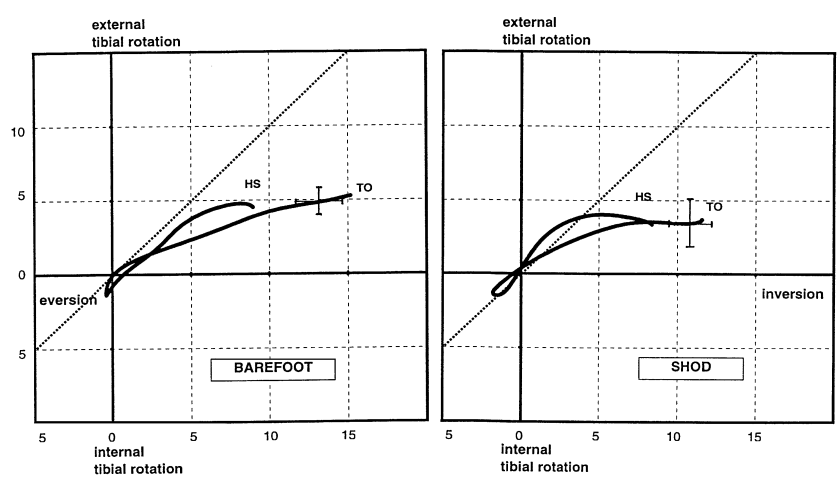

Fig. 2. Mean curve of the relationship between eversion and tibial rotation (subject 1) for barefoot running and running with the normal shoe; mean S.D. are indicated.

between shod and barefoot running were found to be small (around $1^{\circ}$ ) and not systematic (Fig. 3).

\subsection{Barefoot versus shoe modifications}

The comparison between barefoot and shod running including all orthotic and shoe sole modifications showed a few subtle differences:

Touchdown: The calcaneus position at touchdown was inverted except in two trials of subject 3 (see Table 2 of the appendix). In barefoot running the subjects tended to show less inversion on average compared to shod running. Inversion varied across subjects up to $10^{\circ}$. The 

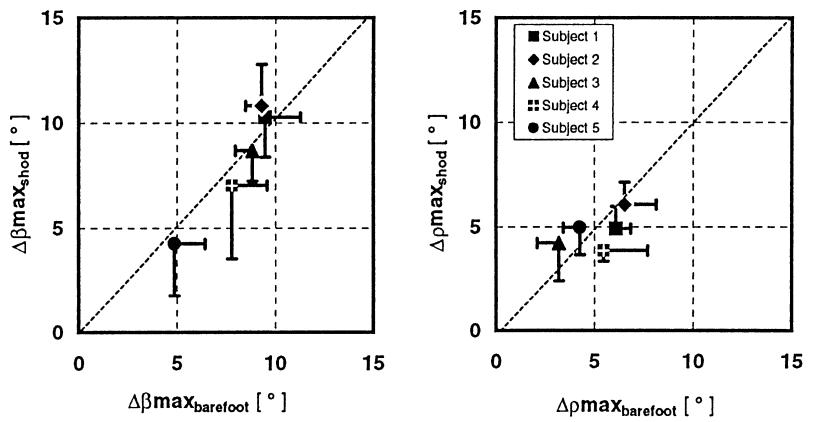

Fig. 3. Total eversion of shod running (normal shoe) versus total eversion of barefoot running (left) and total internal tibial rotation of shod running versus total internal tibial rotation of barefoot running (right) of all five test subjects.

position of the tibia at touchdown was inconsistent across subjects, i.e. externally rotated in subjects 1 and 2, internally rotated in subjects 3 and 4 and varied in subject 5 . The mean differences between the shoe conditions were between 1 and $3^{\circ}$, in contrast to the differences between the subjects which were up to $7^{\circ}$.

Maximum and total movement: Differences between shoe conditions were found to be small (in the order of $1-3^{\circ}$ ) and inconsistent across the five subjects. Total barefoot eversion was found to be very similar to total shod eversion (because the slightly increased maximum eversion was compensated by a smaller touchdown inversion). Internal tibial rotation differences were small, in the order of $1-3^{\circ}$ and inconsistent over the five subjects. The differences between the subjects were up to $7^{\circ}$; the barefoot versus posterior orthosis being the largest difference on average.

Maximum velocity: Barefoot running showed a lower eversion velocity on average compared to shod running. In some subjects maximum eversion velocity was increased over $100^{\circ} / \mathrm{s}$ for the flared and round shoe condition. The slowest internal tibial velocity was that of the posterior orthotic shoe condition.

Movement coupling between the calcaneus and tibia: The coupling coefficient between the barefoot and shod conditions was unsystematic across subjects. With shoes two subjects showed a decreased coupling ratio (subjects 1 and 2), one an increased ratio (subject 3) and two inconsistent results (subjects 4 and 5). The coupling coefficients over all test conditions were subject dependent and varied between 0.4 to 0.5 (subject 3 ) and 0.9 to 1.0 (subject 5). All subjects, except subject 3, showed decreased coupling with the posterior orthosis compared to barefoot running.

\section{Discussion}

The purpose of this study was to quantify the differences in calcaneal and tibial movements during ground contact for running barefoot, with a normal shoe, and with shoe modifications. Previous investigations suggested that total eversion and total internal tibial rotation for barefoot running would be smaller than for running with shoes. These suggestions, could not be confirmed. The results showed that the differences in the study variables of eversion and tibial rotation (Table 1) between barefoot and shod running were small and not systematic across subjects. The differences between subjects were larger than the differences between shoe and barefoot conditions, despite possible measurement errors (see Section 2). Furthermore, it was found that movement coupling between calcaneus and tibia was only minimally affected by normal shoes, shoe sole modifications and orthoses (with the exception of the posterior orthoses).

The investigation was limited by the fact that the test shoes had a cutout in the lateral heel counter that was necessary to prevent impingement with the calcaneal bone pin and that local anesthesia was applied at the bone pin insertion sites. However, there is evidence (Reinschmidt et al., 1997; Stacoff et al., 2000) that these factors did not substantially influence the kinematics during testing.

\subsection{Barefoot versus shod running}

Previous studies using skin and shoe mounted markers have shown substantial and significant differences between barefoot and shod running with respect to foot eversion (Bates et al., 1978; Stacoff et al., 1991; Vagenas and Hoshizaki, 1992). However, these results can not be supported by the present study. The differences in calcaneal eversion between barefoot running and running with normal shoes were small and not systematic. The same result was found for internal tibial rotation and for movement coupling. Consequently, it is suggested that previous studies described the movements of the shoe and/or skin and did not reflect the movement of the underlying bone.

\subsection{Barefoot versus shoe modifications}

Extreme shoe modifications were the flared and the round shoe soles which showed an increased maximum eversion velocity in all, but subject 3 . Both of these shoe sole conditions were unusual. The flare of the sole was $20^{\circ}$ lateral (about twice that of an average running shoe) which may have acted as a lever that forced the foot into eversion. The round shoe sole may have acted as a ramp as a result of the combination of the round sole geometry and the hard outer sole. Another extreme shoe modification was the posterior orthosis which showed the largest reduction in eversion compared to barefoot running. This suggests, that only extreme shoe modifications may affect tibiocalcaneal movement patterns during running. Normal shoes, or less extreme changes, like those in the anterior orthosis and the straight shoe condition, seem not to affect the kinematics measured on the bone level. 
Table 2

Range, mean and SD of eversion, tibial rotation movement coupling $\left(T_{\mathrm{CT}}\right)^{\mathrm{a}}$

\begin{tabular}{|c|c|c|c|c|c|c|c|c|c|}
\hline Variable & Condition & Smallest & & & Largest & & & Mean & SD \\
\hline & Normal & 0.10 & \pm 0.61 & S3 & -8.37 & \pm 1.89 & $\mathrm{~S} 1$ & -4.15 & \pm 3.44 \\
\hline & Posterior & 0.58 & \pm 0.32 & $\mathrm{~S} 3$ & -9.64 & \pm 0.97 & $\mathrm{~S} 1$ & -4.92 & \pm 3.99 \\
\hline & Straight & -1.97 & \pm 1.66 & S3 & -11.22 & \pm 0.87 & $\mathrm{~S} 1$ & -5.29 & \pm 3.90 \\
\hline & Flared & -1.28 & \pm 1.48 & S3 & -11.05 & \pm 2.51 & $\mathrm{~S} 1$ & -5.53 & \pm 4.15 \\
\hline & Round & -1.50 & \pm 0.43 & S3 & -11.15 & \pm 1.45 & $\mathrm{~S} 1$ & -5.02 & \pm 4.06 \\
\hline \multirow[t]{4}{*}{$\beta_{\max }(\operatorname{deg})$} & Barefoot & 0.56 & \pm 1.47 & $\mathrm{~S} 1$ & 6.88 & \pm 0.70 & $\mathrm{~S} 4$ & 4.59 & \pm 2.61 \\
\hline & Straight & -0.77 & \pm 0.20 & $\mathrm{~S} 1$ & 6.45 & \pm 0.52 & $\mathrm{~S} 4$ & 3.51 & \pm 2.96 \\
\hline & Flared & -0.09 & \pm 0.42 & $\mathrm{~S} 1$ & 6.56 & \pm 0.44 & $\mathrm{~S} 4$ & 3.30 & \pm 2.63 \\
\hline & Round & 0.23 & \pm 1.09 & $\mathrm{~S} 1$ & 6.39 & \pm 0.06 & $\mathrm{~S} 3$ & 3.24 & \pm 2.21 \\
\hline \multirow[t]{6}{*}{$\Delta \beta_{\max }(\mathrm{deg})$} & Barefoot & 4.86 & \pm 1.56 & S5 & 9.48 & \pm 1.81 & $\mathrm{~S} 1$ & 8.05 & \pm 1.90 \\
\hline & Normal & 4.26 & \pm 2.46 & S5 & 10.85 & \pm 1.94 & $\mathrm{~S} 2$ & 8.23 & \pm 2.67 \\
\hline & Posterior & 4.08 & \pm 1.73 & S5 & 11.45 & \pm 0.30 & $\mathrm{~S} 1$ & 7.97 & \pm 2.78 \\
\hline & Anterior & 4.32 & \pm 3.19 & S5 & 10.68 & \pm 2.00 & $\mathrm{~S} 1$ & 7.89 & \pm 2.64 \\
\hline & Straight & 5.98 & \pm 2.51 & S5 & 11.09 & \pm 1.09 & $\mathrm{~S} 2$ & 8.80 & \pm 2.05 \\
\hline & Flared & 5.61 & \pm 1.89 & S5 & 11.18 & \pm 3.05 & $\mathrm{~S} 2$ & 8.83 & \pm 2.59 \\
\hline & Straight & 80.84 & \pm 36.97 & S5 & 170.95 & \pm 94.39 & S4 & 131.92 & \pm 33.08 \\
\hline & Flared & 67.72 & \pm 24.54 & S5 & 211.97 & \pm 50.70 & $\mathrm{~S} 4$ & 144.30 & \pm 56.52 \\
\hline & Round & 90.06 & \pm 3.42 & S5 & 191.47 & \pm 41.80 & $\mathrm{~S} 1$ & 141.39 & \pm 40.11 \\
\hline \multirow[t]{7}{*}{$\rho_{0}(\operatorname{deg})$} & Barefoot & 2.19 & \pm 0.82 & $\mathrm{~S} 3$ & -4.55 & \pm 0.67 & $\mathrm{~S} 1$ & -0.24 & \pm 2.83 \\
\hline & Normal & 3.97 & \pm 1.03 & $\mathrm{~S} 3$ & -3.35 & \pm 0.24 & $\mathrm{~S} 1$ & -0.16 & \pm 3.09 \\
\hline & Posterior & 4.11 & \pm 0.99 & $\mathrm{~S} 3$ & -3.52 & \pm 0.24 & $\mathrm{~S} 1$ & 0.24 & \pm 3.64 \\
\hline & Anterior & 3.47 & \pm 1.20 & S4 & -3.94 & \pm 0.56 & $\mathrm{~S} 1$ & -0.27 & \pm 3.35 \\
\hline & Straight & 3.85 & \pm 2.05 & $\mathrm{~S} 4$ & -2.75 & \pm 0.27 & $\mathrm{~S} 1$ & -0.18 & \pm 2.76 \\
\hline & Flared & 3.10 & \pm 0.64 & $\mathrm{~S} 4$ & -2.25 & \pm 0.64 & $\mathrm{~S} 2$ & -0.11 & \pm 2.26 \\
\hline & Round & 3.70 & \pm 1.13 & S4 & -2.52 & \pm 1.03 & $\mathrm{~S} 2$ & -0.43 & \pm 3.32 \\
\hline \multirow[t]{7}{*}{$\rho_{\max }(\mathrm{deg})$} & Barefoot & 1.55 & \pm 0.29 & $\mathrm{~S} 1$ & 7.79 & \pm 1.69 & S4 & 4.87 & \pm 2.26 \\
\hline & Normal & 1.55 & \pm 1.87 & $\mathrm{~S} 1$ & 8.21 & \pm 1.40 & S3 & 4.65 & \pm 2.51 \\
\hline & Posterior & 0.12 & \pm 0.55 & $\mathrm{~S} 1$ & 7.17 & \pm 1.55 & $\mathrm{~S} 3$ & 3.47 & \pm 3.20 \\
\hline & Anterior & 0.14 & \pm 0.44 & $\mathrm{~S} 1$ & 7.90 & \pm 1.37 & S4 & 4.00 & \pm 3.26 \\
\hline & Straight & 1.86 & \pm 0.18 & $\mathrm{~S} 2$ & 9.35 & \pm 1.29 & S4 & 4.32 & \pm 3.04 \\
\hline & Flared & 2.04 & \pm 1.15 & $\mathrm{~S} 1$ & 7.97 & \pm 0.75 & $\mathrm{~S} 4$ & 4.60 & \pm 2.28 \\
\hline & Round & 1.82 & \pm 0.67 & $\mathrm{~S} 1$ & 7.98 & \pm 1.00 & $\mathrm{~S} 4$ & 4.22 & \pm 2.52 \\
\hline
\end{tabular}




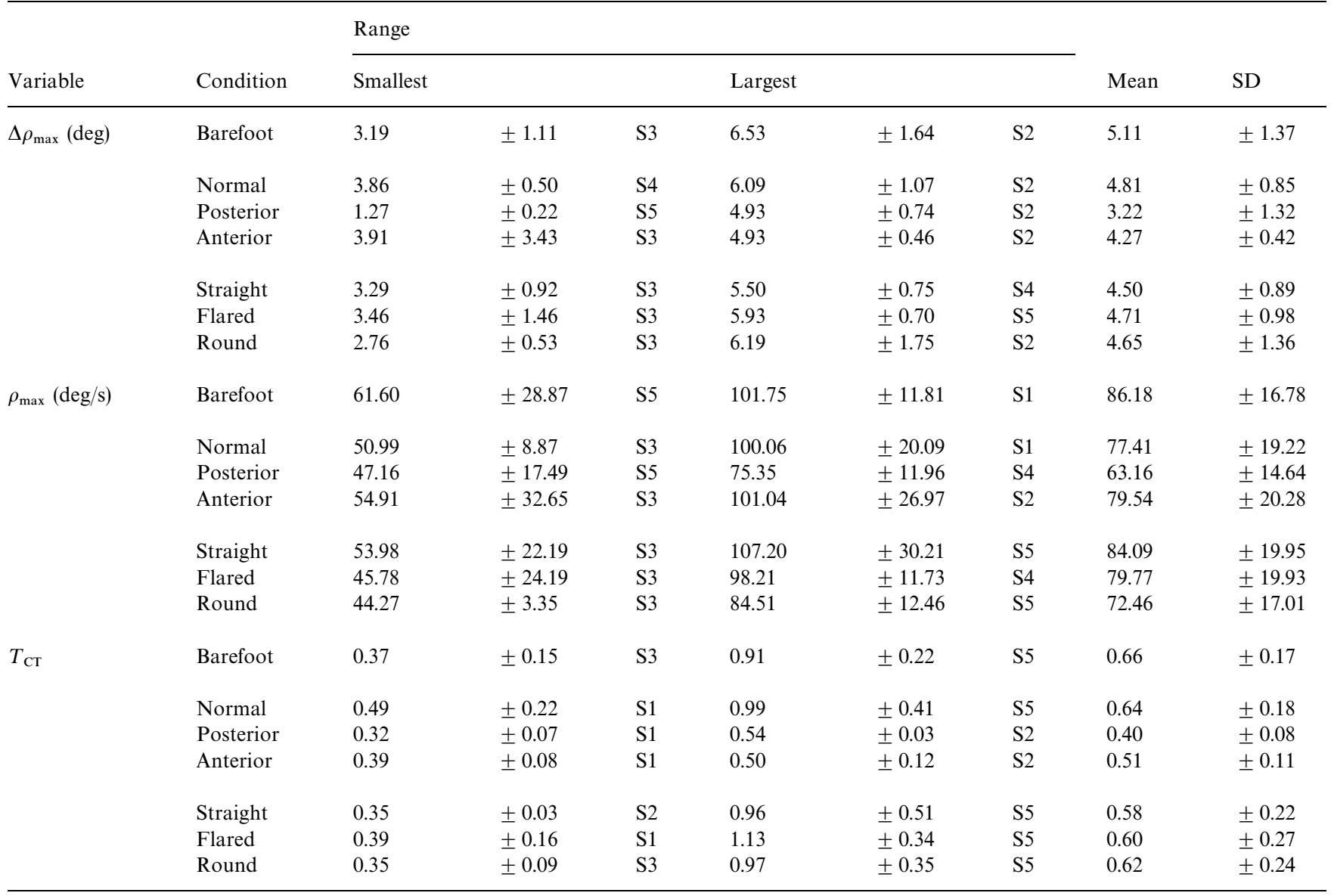

${ }^{a}$ Positive values represent eversion and internal tibial rotation, negative values denote inversion and external tibial rotation. S1-S5 indicate the test subject number.

The results of this study were achieved with clinically normal feet. However, McClay and Manal (1997) showed that the coupling at the ankle may depend on the foot type (normal versus pronator). Thus, it can be argued that kinematic responses of shoe sole modifications may be changed when feet of different types are tested. Furthermore, it is suggested that the results of the present study may be different if higher forces were acting (e.g. at higher running speeds or during cutting movements) and consequently, the effect of the shoe modifications would be more prominent.

\subsection{Interpretation of movement coupling}

The movement coupling coefficient $T_{\mathrm{CT}}$ is the variable used to describe the coupling mechanism between calcaneal eversion and tibial rotation (Fig. 4). All subjects, except subject 3 (possibly due to inaccurate touchdown data, see Fig. 1), showed a decreased coupling ratio with the posterior orthosis compared to barefoot running. The individual differences of the average coupling ratio varied considerably between subjects which suggests that each subject had a different and distinct tibiocalcaneal coupling mechanism.

The present coupling coefficients compare well with those of the in vitro studies by Olerud and Rosendahl (1985, coefficient 0.42) and Hintermann (1994; coefficient $0.74)$, but are larger than those of the in vivo study by Lundberg (1989, coefficient 0.2). Studies using shoe and skin-mounted markers reported average coefficients of 0.76 (Nigg et al., 1993) and 0.72 (McClay and Manal, 1997). Thus, when comparing the coefficients between studies methodological discrepancies must be kept in mind.

\section{Summary}

This in vivo study showed that bone movements during barefoot running are generally very similar to those inside typical running shoes. The normal shoe condition showed no difference relative to barefoot running in 


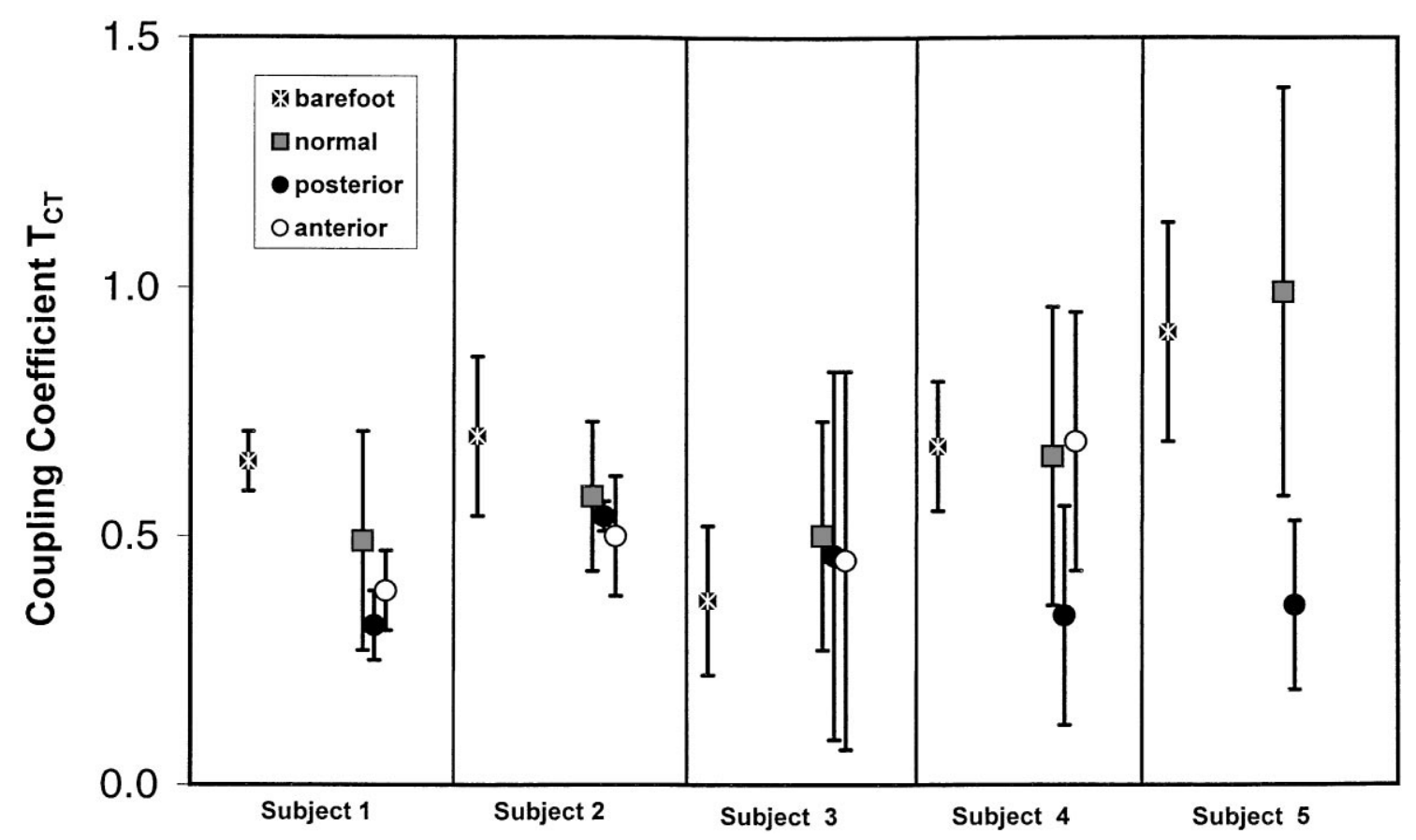

Fig. 4. Coupling coefficients for selected test conditions (for subject 5 the value for the anterior test condition is not available).

either of the test variables. The results of this in vivo study are in contrast with previous investigations using skin and shoe-mounted markers, and suggests that these discrepancies may be the result of the overestimation with externally mounted markers.

The posterior orthosis showed the largest differences to barefoot running in several variables. It is concluded that, measured at the bone level, calcaneal and tibial movement patterns do not differ substantially between barefoot and shod running. However, differences may occur during midstance when extreme shoe modifications (i.e. posterior orthosis) are used.

Future studies in the area of running research may consider the following thoughts: In the present study no information about possible muscular activity changes was collected. However, muscular activity is thought to modulate movement patterns during gait (Zernicke and Smith, 1996) which may produce subtle kinematic changes. Some evidence for this argument is provided by Fromme et al. (1997), who showed that pronation during running is increased over time with increasing fatigue and by Feltner et al. (1994) who demonstrated that strength training can reduce total eversion significantly after eight weeks of training. Therefore, shoe modifications may affect muscular activity and thus lead (over time) to a shift of internal loading towards tissues which have been associated with running injuries. Thus, future studies should try to reveal muscular activity changes as a result of systematically designed shoe modifications and should take into account that one specific shoe modification can result in a variation of individual effects. At the present time it is hypothesised that there are groups of subjects that react to shoe modifications in a similar way. It is suggested that further studies attempt to identify these groups and their characteristics during gait.

\section{Acknowledgements}

This study was supported by the Swedish Defense Material Administration, the Swiss Federal Sports Commission (ESK), the Olympic Oval Endowment Fund of Calgary and ADIDAS America. The help and support of J. Denoth, E. Stüssi, R. Lawson, H. Strebel, and E. Avramakis at various stages of the project was greatly appreciated.

\section{Appendix}

The results and SD of the eversion $(\beta)$ and tibial rotation variables $(\rho)$, and the results of movement coupling $\left(T_{\mathrm{CT}}\right)$ are shown in Table 2.

\section{References}

Areblad, M., Nigg, B.M., Ekstand, J., Olisson, K.O., Ekström, H., 1990. Three-dimensional measurement of rearfoot motion during running. Journal of Biomechanics 23, 933-940. 
Bates, B.T., Osternig, L.R., Mason, B., James, S.L., 1978. Lower extremity function during the support phase of running. In: Asmussen, E., Jorgensen, K. (Eds.), Biomechanics VI-B. University Park, Baltimore, pp. 30-39.

Cappozzo, A., Catani, F., Leardini, A., Benedetti, M.G., Della Croce, U., 1996. Position and orientation in space of bones during movement: experimental artefacts. Clinical Biomechanics 11, 90-100.

Clarke, T.E., Frederick, E.C., Hamill, C., 1984. The study of rearfoot movement in running. In: Frederick, E.C. (Ed.), Sport Shoes and Playing Surfaces. Human kinetics. Champaign, IL, pp. 166-189.

Clement, D.B., Taunton, J.E., Smart, G.W., McNicol, K.L., 1981. A survey of overuse running injuries. The Physician and Sports Medicine 9, 47-58

Cole, G.K., Nigg, B.M., Ronsky, J.L., Yeadon, M.R., 1993. Application of the joint coordinate system to three-dimensional joint attitude and movement representation: a standardization proposal. Journal of Biomechanical Engineering 115, 344-349.

Feltner, M.E., Macrae, H.S.H., Macrae, P.G., Turner, N.S., Hartmann, C.A., Summers, M.L., Welch, M.D., 1994. Strength training effects on rearfoot motion in running. Medicine and Science in Sports and Exercise 26, 1021-1027.

Fromme, A., Winkelmann, F., Thorwesten, L., Reer, R., Jerosch, J., 1997. Dependency of rearfoot pronation on physical strain during running. Sportverletzungen - Sportschaden 11, 52-57.

Hintermann, B., 1994. Die mechanische Kopplung der Sprunggelenke. (The mechanical coupling of the ankle joints.) Habilitationsschrift der Universität Basel.

James, S.L., Bates, B.T., Osternig, L.R., 1978. Injuries to runners. American Journal of Sports Medicine 6, 40-50.

Lundberg, A., 1989. Kinematics of the ankle and foot: in vivo roentgen stereophotogrammetry. Acta Orthopaedica Scandanavia 60 (Suppl. 233), 1-26.

McClay, I.S., Manal, K., 1997. Coupling parameters in runners with normal and excessive pronation. Journal of Applied Biomechanics 13, 109-124.

van Mechelen, W., 1992. Running injuries: a review of the epidemiological literature. Sports Medicine 14, 320-335.

Milani, T.L., Schnabel, G., Hennig, E.M., 1995. Rearfoot motion and pressure distribution patterns during running in shoes with varus and valgus wedges. Journal of Applied Biomechanics 11, 177-187.

Nigg, B.M., Morlock, M., 1987. The influence of lateral heel flare of running shoes on pronation and impact forces. Medicine and Science in Sports and Exercise 19 (3), 294-302.
Nigg, B.M, Cole, G.K., Nachbauer, W., 1993. Effects of arch height of the foot on angular motion of the lower extremities in running. Journal of Biomechanics 26 (8), 909-916.

Olerud, C., Rosendahl, Y., 1985. Torsion-transmitting properties of the hind foot. Clinical Orthopeadics and Related Research 214, 285-294.

Reinschmidt, C., 1996. Three-dimensional tibiocalcaneal and tibiofemoral kinematics during human locomotion - measured with external and bone markers. Ph.D. Thesis, The University of Calgary.

Reinschmidt, C., van den Bogert, A.J., Lundberg, A., Murphy, N., Nigg, B.M., 1997. Tibiocalcaneal motion during running - measured with external and bone markers. Clinical Biomechanics 12 (1), 8-16.

Segesser, B., Nigg, B.M., 1980. Insertionstendinosen am Schienbein, Achillodynie und Überlastungsfolgen am Fuss - Ätiologie, Biomechanik, therapeutische Möglichkeiten. (Tibial insertion tendinoses, achillodynia and damage to overuse of the foot - etiology, biomechanics, therapy.). Orthopaede 9, 207-214.

Stacoff, A., Kälin, X., Stüssi, E., 1991. The effects of shoes on the torsion and rearfoot motion in running. Medicine and Science in Sports and Exercise 23 (4), 482-490.

Stacoff, A., 1998. Skeletal lower extremity motions during running. Ph.D. Thesis, The University of Calgary.

Stacoff, A., Reinschmidt, C., Nigg, B.M., van den Bogert, A.J., Lundberg, A., Denoth, J., Stüssi, E., 2000. Effects of foot orthoses on skeletal motion during running. Clinical Biomechanics 15, 54-64.

Stergiou, P., 1996. Biomechanical factors associated with patellofemoral pain syndrome in runners. Unpublished Master Thesis, The University of Calgary, Alberta, Canada.

Vagenas, G., Hoshizaki, B., 1992. A multivariable analysis of lower extremity kinematic asymmetry in running. Journal of Sports Biomechanics 8, 11-29.

Viitasalo, J.T., Kvist, M., 1983. Some biomechanical aspects of the foot and ankle athletes with and without shin splints. The American Journal of Sports Medicine 11 (3), 125-130.

van Woensel, W., Cavanagh, P.R., 1992. A perturbation study of lower extremity motion during running. Journal of Sports Biomechanics $8,30-47$.

Zernicke, R.F., Smith, J.L., 1996. Biomechanical insights into neural control of movement. In: Rowell, L.B., Shepherd, J.T. (Eds.), Handbook of Physiology, Section 12: Exercise: Regulation and Integration of Multiple Systems. Oxford University Press, New York, pp. 293-330. 